\title{
Erratum to: Exact solutions for a perturbed nonlinear Schrödinger equation by using Bäcklund transformations
}

\author{
Hassan A. Zedan • Eman Alaidarous • S. Shapll
}

Published online: 17 October 2013

(C) Springer Science+Business Media Dordrecht 2013

\section{Erratum to: Nonlinear Dyn \\ DOI 10.1007/s11071-013-1030-5}

The second author's name was incorrect in the original publication. It is correct in this erratum.

The online version of the original article can be found under doi:10.1007/s11071-013-1030-5.

H.A. Zedan · E. Alaidarous

Mathematical Department, Faculty of Science, King

Abdulaziz University, P.O. Box 80203, Jeddah 21589,

Saudi Arabia

H.A. Zedan $(\varangle)$

Mathematical Department, Faculty of Science, Kafr

El-Sheikh University, Kafr El-Sheikh, Egypt

e-mail: hassanzedan2003@yahoo.com

S. Shapll

Mathematical Department, Faculty of Education,

Ain Shams University, Cairo, Egypt 